\title{
Determinants of benzo(a)pyrenediol epoxide adducts to haemoglobin in workers exposed to polycyclic aromatic hydrocarbons
}

\author{
M Ferreira Junior, S Tas, M dell'Omo, G Goormans, J P Buchet, R Lauwerys
}

\begin{abstract}
Objective-The aim was to assess the determinants of benzo(a)pyrenediol epoxide adducts to haemoglobin (BaPDE-Hb) in workers exposed to polycyclic aromatic hydrocarbons (PAHs).

Methods-This was a study of the correlations between the concentrations of PAHs in air, 1-hydroxyprene in urine, and BaPDE-Hb adduct concentration in the blood in 206 men working in steel foundries and one graphite electrode producing plant, taking into consideration confounding factors such as smoking and dietary habits.

Results-BaPDE-Hb adduct concentration was correlated $(r=0.26 ; p=0.0002)$ with the airborne PAH concentration and was influenced by tobacco consumption but not by dietary habits. Benzo(a)pyrene concentration in air, 1-hydroxypyrene concentration in urine, and duration of exposure to PAHs were not associated with the adduct concentration. Conclusion-Although environmental exposure to PAHs was statistically associated with BaPDE-Hb adduct concentration, differences between individual subjects in the metabolism of benzo(a)pyrene probably play an important part in determining the amount of BaPDE-Hb adducts formed.
\end{abstract}

(Occup Environ Med 1994;51:451-455)

Key words: polycyclic aromatic hydrocarbons, benzo(a)pyrene, adducts to haemoglobin

Industrial Toxicology and Occupational Medicine Unit Faculty of Medicine, Catholic University of

Louvain, Brussels,

Belgium

M Ferreira Jr

$S$ Tas

$M$ dell'Omo

G Goormans

J P Buchet

R Lauwerys

Correspondence to:

Professor R Lauwerys,

Industrial Toxicology and

Occupational Medicine

Unit, Catholic

Unit, Catholic

30.54 Clos Chapelle-aux-

Champs, 1200 Brussels,

Belgium.

Accepted for publication

5 April 1994
Occupational exposure to mixtures of chemicals containing benzo(a)pyrene and several other polycyclic aromatic hydrocarbons (PAHs) has been associated with an increased mortality risk from neoplasms. ${ }^{1}$ Different approaches have been proposed for assessing occupational exposure to PAHs-namely, air analysis, skin contact monitoring (for example, by cutaneous pads), and biological analyses. $^{23}$ Several studies have confirmed that 1-hydroxypyrene, a metabolite of pyrene excreted in urine, reflects recent $\mathrm{PAH}$ absorption by all routes. ${ }^{4-7}$

As covalent binding of electrophilic $\mathrm{PAH}$ metabolites to DNA is considered as a critical step in the initiation of cancer, ${ }^{8}$ methods have been developed for the detection of PAHDNA adducts in human tissues and peripheral white blood cells, with the aim of assessing the biologically effective dose and of estimating the risk at the individual level (see dell'Omo and Lauwerys ${ }^{9}$ for a review). Overall evaluation of the available data, however, indicates that these methods are suitable for detecting PAH exposure only on a group basis. ${ }^{10}$ Several factors such as diet, ${ }^{11}$ smoking habits, ${ }^{12}$ between subject differences in the metabolism of PAHs and DNA repair, ${ }^{13}$ and proportion of peripheral monocytes, have been proposed to explain the wide variation in the concentration of PAH-DNA adducts in peripheral white blood cells among subjects with the same estimated occupational exposure. $^{814}$

Because genotoxic compounds can react with haemoglobin and serum proteins to form stable adducts, assessment of PAH-blood protein adducts has been considered as an alternative marker of exposure to PAHs. ${ }^{31516}$ Because the lifetime of haemoglobin in humans is about 120 days, and no enzymatic repair systems exist for haemoglobin, measurement of haemoglobin adducts might reflect the integrated exposure to PAHs over a period of four months before sampling. Therefore, interpretation of haemoglobin adduct measurement might be easier than that of DNA adducts. Despite these apparent advantages, there have been few reports on the detection of PAH-haemoglobin adducts in humans and they mainly focused on the analytical aspects. ${ }^{17-22}$ More data are therefore necessary to establish the real value of this biological marker for assessing human exposure to PAHs. We have measured benzo(a)pyrenediol epoxide haemoglobin (BaPDE-Hb) adducts in workers from two coke oven plants and one graphite electrode plant, and have attempted to identify the factors influencing their concentration.

\section{Subjects and methods}

STUDY POPULATION

A detailed description of the study population can be found in a previous publication. ${ }^{7}$ It involves 286 men working in steel foundries (mainly in two coke ovens and rolling mills) and one graphite electrode producing plant, but measurement of BaPDE-Hb adducts could only be performed on 206 subjects.

Answers from a self administered questionnaire inquiring about present health state, medical history, alimentary, smoking, and alcoholic habits, educational level, dwelling site, and occupational activities were obtained from each participant. 
Each worker was equipped with a personal air sampling pump (model 224 PCEXR3, SKC Inc, Eighty Four, PA, USA, flow rate of $21 / \mathrm{min}$ ) during at least a five hour period of one normal workshift. Particles were retained on a glass microfibre filter (GFF, Whatman, $3.7 \mathrm{~cm}$ diameter) and vapours were adsorbed on a two section Chromosorb 102 tube placed between the pump and the filter. Tubes and filters were kept in a refrigerated dark room until analysis (within two weeks). At the end of the shift samples of blood and urine were collected for the determination of BaPDE-Hb adducts, 1-hydroxypyrene in urine, and other biological variables (see later).

Two criteria were used to classify the workers as being exposed to PAHs: (1) average $\mathrm{PAH}$ concentration in air $>4 \mu \mathrm{g} / \mathrm{m}^{3}$ or (2) 1-hydroxypyrene concentration in urine $>1 \mu \mathrm{g} / \mathrm{g}$ creatinine. These represent the $95 \mathrm{th}$ percentile values of the distributions of PAH concentration in air and 1-hydroxypyrene concentration in the urine of workers not occupationally exposed. ${ }^{?}$

\section{Methods}

DETERMINATION OF PAHS IN AIR

Benzo(a)pyrene and 12 other PAHs (naphthalene, fluorene, phenanthrene, anthracene, fluoranthene, pyrene, benz(a)anthracene, chrysene, benzo(e)pyrene, perylene, dibenz(a)anthracene, and benzo(g,h,i)perylene) were determined by high performance liquid chromatography (HPLC) coupled to fluorometry as previously reported. ${ }^{4}$ Total PAH was calculated as the sum of the 13 PAHs. The results were expressed as $\mu \mathrm{g} / \mathrm{m}^{3}$ of air.

\section{DETERMINATION OF 1-HYDROXYPYRENE IN URINE}

The technique used was that of Jongeneelen $e t$ al. ${ }^{23}$ Results were standardised for urinary creatinine and expressed as $\mu \mathrm{g} / \mathrm{g}$ creatinine.

\section{DETERMINATION OF BaPDE-Hb ADDUCTS}

The BaPDE-Hb adducts were determined by HPLC with fluorescence detection according to a procedure adapted from Shugart. ${ }^{24}$ Briefly it comprised (1) isolation of the red blood cells by centrifugation ( $2000 \mathrm{rpm}$ for $10 \mathrm{~min}$ utes) and lysis of the cells by mixing with distilled water $(\mathrm{v} / \mathrm{v})$; (2) mild acid hydrolysis of the haemoglobin $\left(0 \cdot 1 \mathrm{~N} \mathrm{HCL}\right.$ at $80^{\circ} \mathrm{C}$ for four hours) releasing benzo(a)pyrene (BaPtetrol) (only the isomer $\mathrm{r} 7, \mathrm{t} 8,9, \mathrm{cl} 0 \mathrm{BaPtetrol}$ (tetrol 1-1) was detected); (3) clean up of the hydrolysate on successively, $\alpha \mathrm{C} 18$ cartridge (Varian), diethylaminoethyl-cellulose (DE 32 Whatman), and Bond elut 3-ml phenyl (Varian) columns, elution with methanol, evaporation under a gentle stream of nitrogen, and redispersion in $500 \mu \mathrm{l}$ of methanol; (4) HPLC/fluorescence analysis. Results were calculated from a standard curve with tetrol 1-1 (Midwest Research Institute), standardised for the blood haemoglobin concentration, and expressed in $\mathrm{fmol} \mathrm{BaPtetrol} / \mathrm{mg} \mathrm{Hb}$. The recovery was assessed from $\mathrm{r} 7, \mathrm{t} 8$-dihydroxy- t9,10-epoxy-7,8,9,10-tetrahydrol $\left[1,3{ }^{3} \mathrm{H}\right]$ benzo(a)pyrene (Chemsyn Science Laboratories) as an internal standard.

OTHER BIOLOGICAL ANALYSES

Urinary creatinine was determined by the colorimetric method of Jaffé with slight modifications for automation (Technicon RA1000, Tarrytown, NY, USA).

Urinary thiocyanate concentration was measured by the technique of Pettigrew and Fell. ${ }^{25}$

Urinary ethanol was determined by gas chromatography on a $150 \mathrm{~cm}, 3.2 \mathrm{~mm}$ internal diameter column containing $25 \%$ Carbowax $20 \mathrm{M}$ on Chromosorb WAW DMCS $100-120$ mesh at $90^{\circ} \mathrm{C}$ coupled with a flame ionisation detector.

The hepatic enzymes serum glutamic oxaloacetic transaminase (S-GOT), serum glutamic pyruvic transaminase (S-GPT), and $\gamma$-glutamyl transpeptidase $(\gamma-G T)$ were measured with Biochemica test combination kits (Boehringer Diagnostica, Mannheim GMBH, Germany).

Haemoglobin was analysed by a cyanohaemoglobin procedure.

Serum creatinine was determined by a direct colorimetric method.

Urinary albumin, retinol binding protein (RBP), and $\beta_{2}$-microglobulin $\left(\beta_{2} M\right)$ were determined by automated non-isotopic immunoassays based on latex particle agglutination. ${ }^{26}$

Urinary $\mathrm{N}$-acetyl- $\beta$-D-glucosaminidase (NAG) was measured by the fluorimetric method described by Tucker et al. ${ }^{27}$

\section{STATISTICAL ANALYSIS}

Responses to the questionnaire and analytical data were stored in a database and statistically analysed with SAS/STAT software. ${ }^{28}$ When necessary (Wilk's test), distributions were normalised by log transformation.

The statistical significance for differences between means was assessed by Student's $t$ test.

A stepwise regression analysis was performed to identify the statistically significant determinants of BaPDE-Hb adducts. As well as the exposure variables (benzo(a)pyrene or total PAHs in air or 1-hydroxypyrene in urine) the various determinants introduced in the model were age, urinary thiocyanate, urinary ethanol, number of cups of coffee daily, risk food index $(0=$ no regular consumption of grilled and fried foods; 1 = regular consumption of these food items), protective food index $(0=$ no regular consumption of fruits and juices; $1=$ regular consumption of these food items), dwelling site $(0=$ urban area; $1=$ countryside $),$ plant ( $0=$ coke oven; $1=$ graphite electrode), renal and hepatic indices $(0=$ none of the renal variables (serum creatinine, urinary albumin, RBP, NAG, $\beta_{2} M$ ) or the serum hepatic enzymes (S-GOT, S-GPT, and $\gamma-G T$ ) exceeding the 95th percentile of the corresponding distribution in the control group; 1 = at least one renal or hepatic variable above this value). The procedure ended 
Table 1 Concentration of $\mathrm{BaPDE}-\mathrm{Hb}$ adducts (fmol/mg $\mathrm{Hb}$ ) according to the concentration of PAHs in air and 1-hydroxypyrene (1-HOP) in urine

\begin{tabular}{|c|c|c|c|}
\hline Exposure variable & No of subjects & $B a P D E-H b$ adducts & p Value \\
\hline $\begin{array}{l}\text { PAHs in air }\left(\mu \mathrm{g} / \mathrm{m}^{3}\right): \\
\quad \leqslant 4 \cdot 0\end{array}$ & 113 & $\begin{array}{l}24 \cdot 3(2 \cdot 5)^{\star} \\
(5 \cdot 0-169 \cdot 8) \dagger\end{array}$ & \multirow{2}{*}{0.03} \\
\hline$>4 \cdot 0$ & 93 & $\begin{array}{l}31 \cdot 8(2 \cdot 3) \\
(5 \cdot 0-139 \cdot 3)\end{array}$ & \\
\hline $\begin{array}{l}\text { 1-HOP in urine }(\mu \mathrm{g} / \mathrm{g} \text { creatinine }): \neq \\
\leqslant 2 \cdot 0\end{array}$ & 139 & $\begin{array}{l}27 \cdot 2(2 \cdot 4)^{\star} \\
(5 \cdot 0-169 \cdot 8) \dagger\end{array}$ & \multirow{2}{*}{ NS } \\
\hline$>2 \cdot 0$ & 64 & $\begin{array}{l}27 \cdot 7(2 \cdot 5) \\
(5 \cdot 0-130 \cdot 2)\end{array}$ & \\
\hline
\end{tabular}

${ }^{\star}$ Geometric mean (SD). $\nmid$ Range. $¥$ Three workers failed to give a urine sample at the end of the workshift.

Table 2 Determinants of BaPDE-Hb adducts (multiple regression analysis) in the total population

\begin{tabular}{llcll}
\hline Variable & Determinants & $\begin{array}{l}\text { Partial regression } \\
\text { coefficient }\end{array}$ & $\begin{array}{l}\text { Partial correlation } \\
\text { coefficient }\left(r^{2}\right)\end{array}$ & $p$ Value \\
\hline BaPDE-Hb adducts & PAHs in air & 0.107 & 0.062 & 0.003 \\
& Thiocyanate in urine & 0.304 & 0.031 & 0.01 \\
& Renal index & -0.18 & 0.024 & 0.02
\end{tabular}

* Determinants included in the regression models are: benzo(a)pyrene or total PAH concentration in air or 1 hydroxypyrene in postshift urine, thiocyanate in urine, ethanol in urine, coffee index (juices and fruits), age, dwelling site, renal index, hepatic index, and type of plant.

Association between total polycyclic aromatic hydrocarbons (PAH) concentration in air and results are standardised to a urinary thiocyanate excretion of $3.5 \mathrm{mg} / \mathrm{g}$ creatinine (non-smoker group mean) and to the absence of renal impairment (renal index $=0)$. Broken lines are $95 \%$ confidence intervals. when all the regression coefficients in the model were significant at the $5 \%$ level of probability. For the exposed workers, duration of exposure was also introduced in the model.

The concentration of BaPDE-Hb adducts was considered significantly increased when it exceeded $70 \mathrm{fmol} / \mathrm{mg}$ haemoglobin (95th percentile concentration in the group of workers not exposed to PAHs). The possible determinants of increased values of this variable were tested by applying a logistic regression model to the data. The $95 \%$ confidence level was used to assess statistical significance.

\section{Results}

The mean concentration of BaPDE-Hb adducts was significantly increased in workers ( $n=93$ ) with a time weighted average exposure to PAHs above $4.0 \mu \mathrm{g} / \mathrm{m}^{3}$ (table 1 ). No significant difference between adduct mean concentrations was found when the 1hydroxypyrene concentration in urine was used as the exposure criterion. The multiple regression analysis performed on the total population identified concentration of PAHs, thiocyanate concentration in urine (used as biological indicator of smoking habits), and renal index as statistically significant determinants of $\mathrm{BaPDE}-\mathrm{Hb}$ adduct concentration (figure; table 2). The 1-hydroxypyrene concentration in urine was not associated with the concentration of BaPDE-Hb adducts and surprisingly the time weighted average exposure to $\mathrm{BaP}$ alone was not a significant determinant.

The possible effect of the duration of occupational exposure to PAHs (mean $=10.5$ (range 0.25-30.9) years) on the concentration of $\mathrm{BaPDE}-\mathrm{Hb}$ adducts was tested with linear regression models including the variables mentioned. The models were applied to the workers exposed to PAHs, classified either on the basis of PAH concentration in air $(n=93)$ or 1-hydroxypyrene concentration in urine $(n=64)$. Neither model showed duration of exposure as a significant determinant of BaPDE-Hb adduct concentration.

In the logistic regression model, none of the exposure variables (PAHs in air, benzo(a)pyrene in air, 1-hydroxypyrene in urine, duration of exposure) emerged as a significant determinant of an increased prevalence of increased values ( $>70 \mathrm{fmol} / \mathrm{mg}$ $\mathrm{Hb}$ ) of BaPDE-Hb adducts (results not shown).

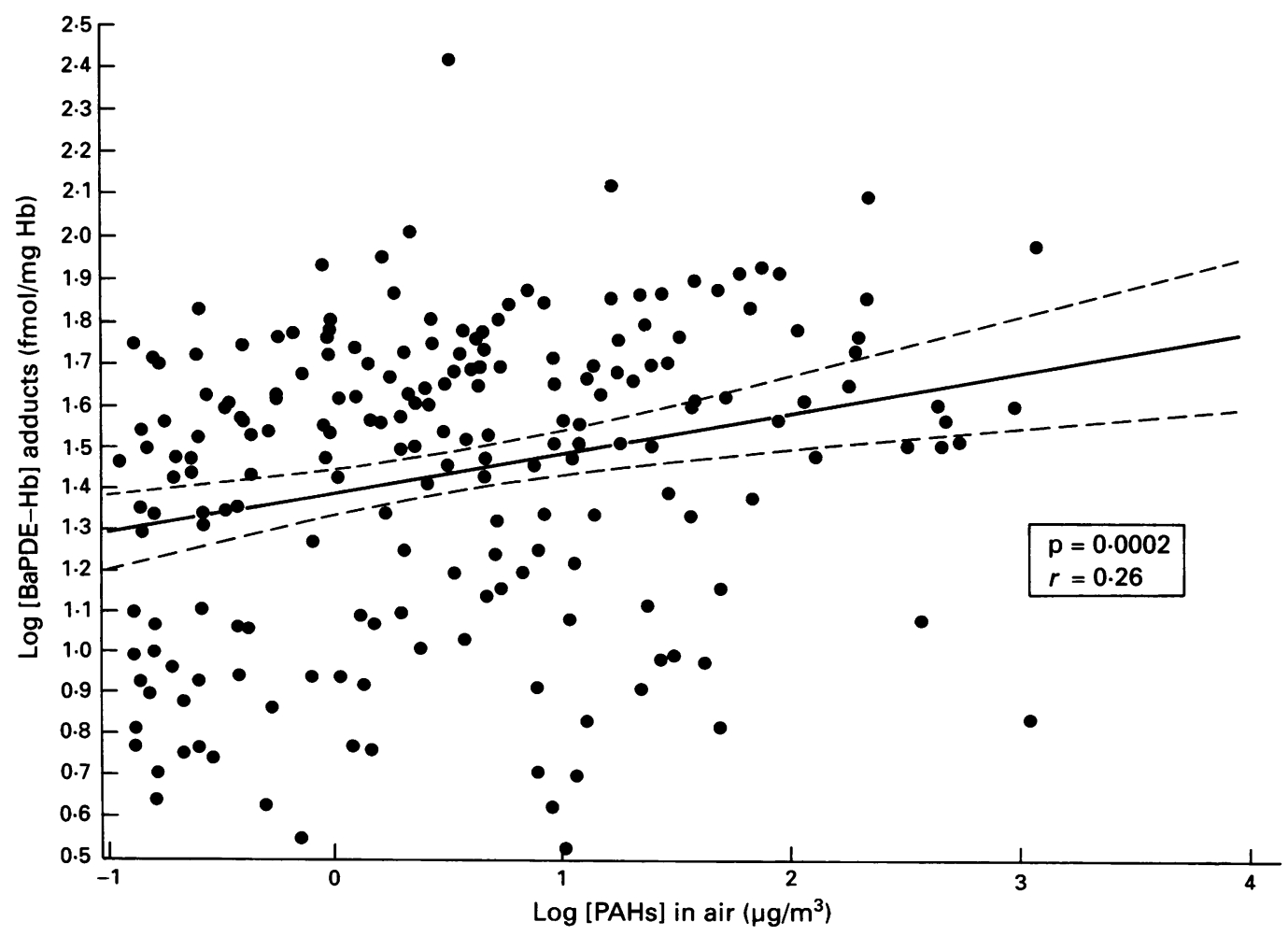




\section{Discussion}

So far, no large scale epidemiological study has been carried out involving the monitoring of PAH-Hb adducts in workers exposed to PAHs. We have previously reported that in the plants in which the present study was carried out, the proportion of the measured airborne PAHs (particularly the sum of the three carcinogenic compounds, benz(a) anthracene, benzo(a)pyrene, and dibenz $(a, h)$ anthracene) was similar and correlated with 1hydroxypyrene in urine. ${ }^{4}$ Therefore, benzo(a) pyrene was selected as the prototype of PAHs and we have attempted to determine whether $\mathrm{BaPDE}-\mathrm{Hb}$ concentration was associated with some exposure variables (benzo(a)pyrene and total PAHs in air, 1-hydroxypyrene in urine, duration of exposure) and possible confounders (smoking and dietary habits, residence, renal, and hepatic function).

We noted that when the total PAHs in air was used as the criterion of exposure, mean $\mathrm{BaPDE}-\mathrm{Hb}$ adduct concentration was higher in the exposed than in the control workers. This is in line with the higher concentration of PAH-protein adducts found by Sherson et al $^{29}$ in exposed foundry workers. The multivariable regression analysis however, showed that although the total concentrations of PAHs in air was the main determinant of BaPDE-Hb adduct concentrations, it only explained $6 \%$ of their variance. Smoking habits (assessed by the thiocyanate concentration in urine) ${ }^{30}$ also influenced the amount of adduct detected, but no significant association was found with 1-hydroxypyrene in urine (an indicator of the overall amount of PAHs recently absorbed), benzo(a)pyrene in air, or duration of exposure. It should be noted that some authors ${ }^{12} 31$ also did not find an association between PAHDNA adducts in peripheral lymphocytes and total PAHs in air or 1-hydroxypyrene in urine. One has to keep in mind that both benzo(a) pyrene in air and 1-hydroxypyrene in urine reflect recent exposure whereas BaPDE-Hb adducts may integrate exposure over a four month period. The impact of tobacco consumption on BaPDE-Hb adduct concentration also reported by Weston et al ${ }^{18}$ may result from the presence of PAHs in tobacco smoke, increased occupational exposure to PAHs due to smoking at the workplace, or possible interference of tobacco smoke on benzo(a)pyrene biotransformation by enzymatic induction. As renal function declines with age, the negative association between the renal index and the BaPDE-Hb adduct concentration could be due to a selection bias; the more polluted workplaces in the plants might have been allotted to the youngest workers. This explanation is unlikely as age was not indentified as a confounder in the multiple regression model tested and no significant difference was found between the mean age of exposed workers with or without abnormal renal variables. It should be noted, however, that none of the renal markers was specifically responsible for this association.

In conclusion, the results suggest that although environmental exposure to PAHs is statistically correlated with the amount of BaPDE-Hb adducts (figure), it is not the main determinant as it only explains $6 \%$ of their variability. It is possible that endogenous toxicokinetic factors (interindividual differences in the metabolism of benzo(a)pyrene) ${ }^{13}$ may be critical in determining the amount of haemoglobin adduct formed. The interest in $\mathrm{BaPDE}-\mathrm{Hb}$ adduct measurement to reflect the biologically active dose of benzo(a)pyrene remains to be established. Assessment of their relation with markers of genotoxic effects (for example, sister chromatid exchanges and chromosomal aberrations in peripheral lymphocytes), and of susceptibility may help clarify this question.

This study was supported by the European Community of Coal and Steel and the Belgian State (Prime Minister's Service-Science Policy Office). Dr M dell'Omo and Dr S Tas were the recipients of a grant from the Brussels-Capital Region.

1 International Agency for Research on Cancer. Polynuclear aromatic compounds. Part 3: industrial exposure in aluminium production, coal gasification, coke production, and iron and steel founding. IARC Monographs on the Carcinogenic Risk of Chemicals to Humans 1984;34 101-31.

2 Reuterwall C, Aringer L, Elinder CG, Rannug A, Levin JO, Juringe L, Önflet A. Assessment of genotoxic exposure in Swedish coke-oven work by different methods of biological monitoring. Scand $f$ Work Environ Health 1991;17:123-32.

3 van Welie RTH, van Dijk RGJM, Vermeulen NPE, Vansittert NJ. Mercapturic acids, protein adducts, and DNA adducts as biomarkers of electrophilic chemicals. Crit Rev Toxicol 1992;22:271-06.

4 Buchet JP, Gennart JP, Mercado-Calderon F Delavignette JP, Cupers L, Lauwerys R. Evaluation of exposure to polycyclic aromatic hydrocarbons in a coke production and a graphite electrode manufacturing plant: assessment of urinary excretion of 1-hydroxypyrene as a biological indicator of exposure. $\mathrm{Br} \mathcal{F}$ Ind Med 1992;49:761-8.

5 Tolos WP, Shaw PB, Lowry LK, Mackenzie BA, Deng JF, Markel HL. 1-Pyrenol: a biomarker for ocupational exposure to polycyclic aromatic hydrocarbons. Applied Occupational and Environmental Hygiene 1990;5:303-9.

6 VanRooij JGM, Bodelier-Bade MM, Jongeneelen FJ. Estimation of individual dermal and respiratory uptake of polycyclic aromatic hydrocarbons in 12 coke oven of polycyclic aromatic hydrocarbons
workers. $\mathrm{Br} \Im$ Ind Med 1993;50:623-32.

7 Ferreira Junior M, Buchet JP, Burrion JB, Moro J, Cupers $\mathrm{L}$, Delavignette JP, et al. Determinants of urinary thioethers, D-glucaric acid and mutagenicity after exposure to polycyclic aromatic hydrocarbons assessed by air monitoring and measurement of 1-hydroxypyrene in urine: a cross sectional study in workers of coke and graphite electrode producing plants. Int Arch Occup Environ Health 1994;65:329-38.

8 Weinstein IB. The origin of human cancer. Molecular mechanism of carcinogenesis and their implications for cancer prevention and treatment. Cancer Res 1988;48. 4135-43.

9 dell'Omo M, Lauwerys $R$. Adducts to macromolecules in the biological monitoring of workers exposed to polycyclic aromatic hydrocarbons. Crit Rev Toxicol 1993;23: cyclic arom

10 Commission of the European Communities. Indicators for assessing exposure and biological effects of genotoxic chemicals. Consensus and technical reports. In: Aitio A Becking G, Berlin A, Bernard A, Foa V, Kello D, et al, eds. Luxembourg: CEC Directorate-General, 1988.

11 Rothman N, Poirier MC, Haas RA, Correa-Villasenor A, Ford P, Hausen JA, et al. Association between PAHDNA adducts in peripheral white blood cells with dietary exposure to polyaromatic hydrocarbons. Environ Health Perspect 1993;99:265-7.

12 van Schooten FJ, van Leuven FE, Hillebrand MJX, de Rijke ME, Hart AAM, van Veen HG, et al. Determination of benzo(a)pyrene diol epoxide-DNA adducts in white blood cell DNA from coke-oven workers: the impact of smoking. F Natl Cancer Inst 1990; 82:927-33.

13 Harris CC. Interindividual variation among humans in carcinogen metabolism, DNA adduct formation and carcinogen metabolism, DNA adduct form

14 Perera F, Brenner D, Jeffrey A, Mayer J, Tang D, Warburton D, et al. DNA adducts and related biomarkers in populations exposed to environmental carcinogens. Environ Health Perpect 1992;98:133-8. 
15 Skipper PL, Tannenbaum SR. Protein adducts in the molecular dosimetry of chemical carcinogens. Carcinogenesis 1990;11:507-18.

16 Neumann HG. Analysis of hemoglobin as a dose monitor for alkylating and arylating agents. Arch Toxicol 1984; 56:1-6.

17 Lee BM, Santella R. Quantitation of protein adducts as a marker of genotoxic exposure:immunologic detection of benzo(a)pyrene-globin adducts in mice. Carcinogenesis 1988;9:1773-7.

18 Weston A, Rowe ML, Manchester DK, Farmer PB, Mann DL, Harris CC. Fluorescence and mass spectral evidence for the formation of benzo(a)pyrene anti-diolepoxide-DNA and -hemoglobin adducts in humans. Carcinogenesis 1989;10:251-7.

19 Naylor S, Gan L, Day BW, Skipper PL, Tannenbaum SR. A rapid method for isolation of human hemoglobin benzo[a]pyrene diol epoxide derived adducts using high performance liquid chromatography. Biomed Chromatogr performance liqui.

20 Jankoviak R, Day BW, Lu PQ, Doxtader MM, Skipper PL, Tannenbaum SR, Small GJ. Fluorescence line narrowing spectral analysis of in vivo human hemoglobin rowing spectral analysis of in vivo human hemoglobin adducts: comparison to synthetic analogues. Foun

21 Bjelogrlic N, Vähäkangas K. Benzo(a)pyrene-globin adducts detected by synchronous fluorescence spectrophotometry: method development and relation to lung DNA adducts in mice. Carcinogenesis 1991;12: $2205-9$.

22 Day BW, Naylor S, Gan LS, Sahali Y, Nguyen TT, Skipper PL, et al. Molecular dosimetry of polycyclic aromatic hydrocarbon epoxides and diol epoxides via hemoglobin adducts. Cancer Res 1990;50:4611-8. 23 Jongeneelen FJ, Anzion RBM, Henderson PT. Determination of hydroxylated metabolites of polycyclic aromatic hydrocarbons in urine. $f$ Chromatogr 1987;413: 227-32.

24 Shugart L. Quantitating exposure to chemical carcinogens: in vivo alkylation of hemoglobin by benzo(a)pyrene.

25 Pettigrew AR, Fell GS. Simplified colorimetric determination of thiocyanate in biological fluids, and its application to investigation of toxic amblyopias. Clin Chem 1972;18:996-1000.

26 Bernard A, Lauwerys R. Continuous flow system for automation of latex immunoassay by particle counting. Clin Chem 1983;29:1007-11.

27 Tucker SM, Boyd PJR, Thompson AD, Price RG. Automatic assay of $\mathrm{N}$-acetyl- $\beta$-D-glucosaminidase in normal and pathological urine. Clin Chim Acta 1975; 62:333-9.

28 SAS/STAT. Guide for personal computers version 6. Cary, NC: SAS Institute, 1987

29 Sherson D, Sabro P, Sigsgaard T, Johansen F, Autrup H. Biological monitoring of foundry workers exposed to polycyclic aromatic

30 Pré J, Vassy R. Urine thiocyanate:creatinine ratio as a reliable indicator of cigarette smoking. Clin Chim Acta 1991;204:87-94.

31 Hemminki K, Grzybowskova E, Chorazy M, Twardowska-Saucha K, Sroczynski JW, Putman KL, et al. DNA Adducts in human environmentally exposed to aromatic compounds in an industrial area of Poland. Carcinogenesis 1990;11:1229-31.
Occupational and Environmental Medicine welcomes correspondence relating to any of the material appearing in the journal. Results from preliminary or small scale studies may also be published in the correspondence column if this seems appropriate. Letters should be not more than 500 words in length and contain a minimum of references. Tables and figures should be kept to an absolute minimum. Letters are accepted on the understanding that they may be subject to editorial revision and shortening.

The journal also publishes editorials which are normally specially commissioned. The Editor welcomes suggestions regarding suitable topics; those wishing to submit an editorial, however, should do so only after discussion with the Editor. 